\title{
Evaluation by electron beam computed tomography of intracardiac masses suspected by transoesophageal echocardiography
}

\author{
E Mousseaux, A Hernigou, M Azencot, M Sapoval, M Auguste, J C Gaux
}

\begin{abstract}
Objectives-To assess the suitability of electron beam computed tomography (EBT) in evaluating and subsequently managing cardiac masses suspected as a result of examination by transthoracic and transoesophageal cross sectional echocardiography.

Design and patients-In 76 consecutive patients with suspected cardiac masses, the impact of the EBT examination was analysed by reviewing whether EBT examination altered management by confirming or excluding a mass, whether EBT imaging substantially contributed to decision-making, and lastly whether EBT influenced the decision to operate on the patient.
\end{abstract}

Results-EBT modified the diagnosis or confirmed results which had been questionable with cross sectional echocardiography in 53 cases (70\%): these cases included those with anatomical features such as dense calcifications or fatty structures $(n=20)$, lipomatous lesions $(\mathbf{n}=5)$, equivocal thrombi $(\mathbf{n}=5)$, pericardial masses $(n=5)$, or hydatid cysts $(n=2)$. EBT gave information over and above cross sectional echocardiography in all patients with malignant tumours ( $n$ $=16$ ) by providing a better delineation of the relation between intracavity masses and normal structures, including the mural site of tumour attachment and tumour extension to the great vessels and the adjacent extracardiac mediastinal structures. EBT provided no additional information over cross sectional echocardiography in the remaining patients $(n=$ 23), particularly in those with myxomas $(n=11)$ or small valvar lesions $(n=6)$. EBT only confirmed that the lesion was well demarcated, limited in extent, or not associated with a mass.

Conclusions-EBT has considerable potential for clinical management and surgical planning and may help clinicians to decide against surgery, particularly in patients with unresectable tumours.

(Heart 1996;76:256-263)

Keywords: neoplasms; computed tomography studies; thrombosis

At present, cross sectional echocardiography is the primary technique used in evaluating patients who are clinically likely to have a cardiac mass. Although transthoracic echocardiography (TTE) produces adequate images in most adult patients, image quality is suboptimal in some. Transoesophageal echocardiography (TOE) has overcome many of the limitations of TTE, and provides high-quality cardiac imaging. Recent studies have demonstrated that TOE is more sensitive than TTE for detecting cardiac thrombi and other sources of systemic embolism. ${ }^{1-4}$ TOE has also recently emerged as a very promising tool for identifying other cardiac masses, ${ }^{58}$ particularly vegetations and cardiac abscesses. ${ }^{9}{ }^{10}$ However, perhaps owing to the wide disparity in both clinical circumstances and anatomical features, diagnosis and the extent of cardiac masses can still be equivocal with TOE. Previous papers have reported the results obtained with electron beam computed tomography (EBT) $)^{11-15}$ or magnetic resonance imaging (MRI) for cardiac masses previously detected by TTE. ${ }^{16-24}$ But none of these papers explored the contribution of EBT or MRI in patients who had undergone complete cross sectional echocardiography by both TTE and TOE examinations. This study was therefore performed to assess the usefulness of EBT for evaluating and subsequently managing cardiac masses previously suggested by these two echocardiographic methods.

We excluded patients with an obvious cross sectional echocardiographic diagnosis, such as thrombus, abscess, or vegetative lesions in bacterial endocarditis. This was because when both clinical circumstances and non-equivocal results of TOE suggest such lesions no further cardiac imaging methods are required.

\section{Patients and methods}

STUDY POPULATION

A total of 76 consecutive patients were examined by EBT to evaluate suspected or known intracardiac masses. Thirty nine male and 37 female patients, aged 57 (17) years (range 16 to 86) were initially evaluated by cross sectional echocardiography, by both TTE and TOE. All cross sectional echocardiographic and EBT examinations were performed within two weeks of each other. Patients with typical cross sectional echocardiographic features of thrombi, identified using one or more of the following criteria, were excluded from this study: lesions arising from mural surfaces in a region of the left ventricle where there were segmental wall motion abnormalities, lesions within an enlarged or fibrillating left atria with 
simultaneous mitral valve disease, and lesions within left atrial appendages. TOE was performed by experienced operators from several cardiology departments using single-plane, biplane, or multiplane $5 \mathrm{MHz}$ transoesophageal transducers connected to a variety of cross sectional echocardiography instruments.

\section{ELECTRON BEAM CT EXAMINATIONS}

A $100 \mathrm{~ms}$ scan acquisition time (C-100 Imatron, South San Francisco, CA) was used to obtain high quality images of the heart and its surrounding structures. ${ }^{14}{ }^{25-27}$ In all patients, a 26 or $30 \mathrm{~cm}$ diameter reconstruction with a $512 \times 512$ matrix and sections 3 or $6 \mathrm{~mm}$ thick were used. Baseline studies were performed using one or two series of unenhanced and contrast-enhanced contiguous scans from the aortic arch to the diaphragm. During the enhanced imaging, a $2 \mathrm{ml} / \mathrm{s}$ intravenous nonionic iodinated contrast medium was delivered over $40 \mathrm{~s}$ using a powered injector. In order to obtain EBT examinations tailored to the clinical presentations and results of cross sectional echocardiographic imaging, patients could be further assessed by cine-mode (scanning time of $50 \mathrm{~ms}$ per image) and ECG gating. All EBT examinations and interpretations were performed in the same institution by one of two radiologists experienced in cardiac studies, who had full knowledge of the patients' clinical and previous imaging records. All examinations were re-evaluated by the two radiologists together to obtain a consensus. The precise locations of cardiac masses, myocardial extension, involvement of surrounding mediastinal structures were noted in all cases. The impact of EBT on the decisionmaking process was then analysed in terms of confirming the mass and by further defining

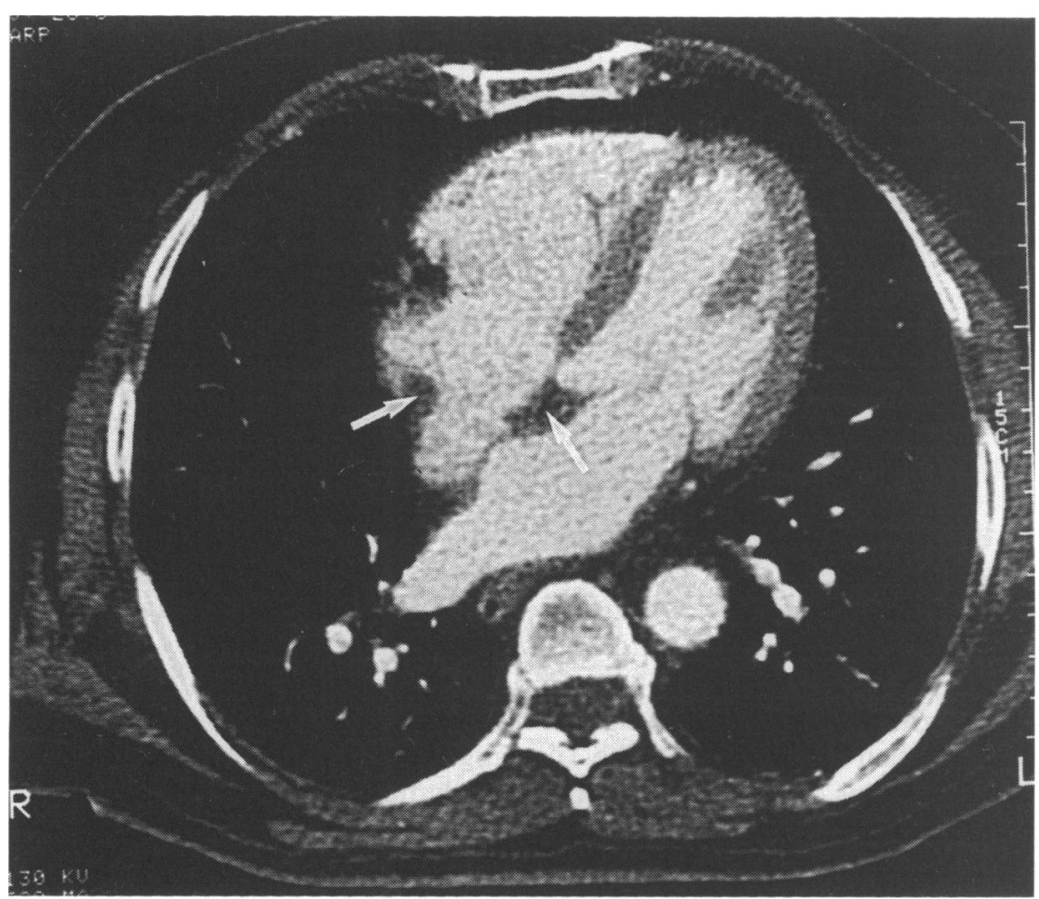

Figure 1 Right atrial thrombus or tumour was suspected from TOE. This EBT image shows a nodular thickening of the lateral wall of the right atrium (arrow) caused by hypertrophic crista terminalis muscle bundle. This case also shows fatty infiltration of the atrial septum not involving the foramen ovale (curved arrow). the anatomy and extent of the tumour. We assessed the impact of the EBT examination on patient management by reviewing the patient's notes with the clinician and/or echocardiographer who referred each patient and by determining both the diagnosis and the decision to operate on the patient before and after the EBT examination. Information compiled about each patient's clinical condition, cross sectional echocardiographic features, surgical procedure, and clinical outcome was available at the time of this second evaluation.

\section{Results}

The study population was divided into two groups on the basis of the EBT findings. Group $1(n=20)$ consisted of those patients in whom an EBT showed no intracardiac mass but did show anatomical features that explained the suspicious findings seen at cross sectional echocardiography. Group 2 ( $n=$ 56) consisted of those patients in whom an intracardiac mass was confirmed by EBT.

\section{GROUP 1}

In $20(26 \%)$ of the 76 patients, EBT showed no intracardiac mass but instead it showed an anatomical structure of a similar size and location that explained the cross sectional echocardiographic findings. In four cases EBT showed dense focal calcification which had been interpreted on cross sectional echocardiography as a possible mass(es). EBT examination in six patients showed that the cross sectional echocardiographic findings were attributable to fatty structures. In six other patients, nodular thickening of the posterolateral wall of the right atrium, attributed to prominence of the crista terminalis muscle bundle, was clearly demonstrated by EBT (fig 1). On TOE images this area of thickening, with variable amounts of muscular and fatty elements, resembled a mass lesion extending across the atrial chamber. Similar confusion arose in the single case of a potential left atrial mass, which EBT showed to be a nodular fibrous structure along the superior pulmonary vein. In two cases a prominent fibromuscular band related to right ventricular hypertrophy apparently contributed to the false positive TOE diagnosis. Finally, a localised small nodular thickening in a pericardial recess over the left atrium detected with EBT had been regarded by TOE as possibly being a small atypical myxoma attached to the top of the left atrium.

GROUP 2

EBT detected pathological lesions in 56 (74\%) of the 76 patients examined; 35 had myocardial or intraluminal masses, seven had masses with pericardial but without myocardial involvement, and 14 had masses which involved both the myocardium and the adjacent pericardium. Histological findings were abnormal in 32 patients: after surgical resection of the mass in 19 patients; after biopsy of mediastinal lesions involving the pericardium and/or the myocardium in eight patients; and at necropsy in three patients. We assumed that 
Table 1 Results of studies on group 2 patients with benign masses

\begin{tabular}{|c|c|c|c|}
\hline $\begin{array}{l}\text { Number of } \\
\text { masses }\end{array}$ & $\begin{array}{l}\text { Cross sectional } \\
\text { echocardiography (CSE) }\end{array}$ & $E B T$ imaging & Verification \\
\hline 11 Myxomas & $\begin{array}{l}9 \text { Typical left atrial } \\
\text { myxomas arising from } \\
\text { atrial septum and } 2 \\
\text { possible neoplasms }\end{array}$ & Similar conclusion as CSE & Pathology in all cases \\
\hline 7 Lipomatous lesions & $\begin{array}{l}1 \text { Endoluminal LV tumour, } \\
1 \text { pericardial mass, } \\
2 \text { likely lipomatous } \\
\text { infiltrations of the atrial septum, } \\
2 \text { LA thrombi or tumours, } \\
1 \text { possible RA myxoma }\end{array}$ & $\begin{array}{l}2 \text { True lipomas, } \\
5 \text { lipomatous infiltrations } \\
\text { of the atrial septum }\end{array}$ & None \\
\hline 8 Thrombi & $\begin{array}{l}3 \text { Possible tumours, } \\
5 \text { equivocal thrombi }\end{array}$ & $\begin{array}{l}3 \text { Possible endoluminal tumours, } \\
5 \text { unusual thrombi }\end{array}$ & \multirow{2}{*}{$\begin{array}{l}\text { Pathology in } 3 \text { cases, } \\
\text { disappearance of lesions } \\
\text { on follow up in } 5 \text { cases } \\
\text { Pathology in a non- } \\
\text { specific pericardial } \\
\text { inflammation and in a } \\
\text { serohaemorrhagic cyst }\end{array}$} \\
\hline 6 Pericardial lesions & $\begin{array}{l}1 \text { Atypical thrombus, } \\
1 \text { likely pericardial haematoma, } \\
1 \text { possible RA tumour, } \\
3 \text { possible pericardial tumours }\end{array}$ & $\begin{array}{l}\text { Pericardial location was } \\
\text { demonstrated in all cases; } \\
\text { absence of enhancement after } \\
\mathrm{CM} \text { injection in } 3 \text { old haematomas } \\
\text { and } 1 \text { cyst, } 1 \text { serohaemorrhagic cyst; } \\
1 \text { case was a possible tumour }\end{array}$ & \\
\hline $\begin{array}{l}2 \text { Hydatid cysts } \\
6 \text { Vavle lesions }\end{array}$ & $\begin{array}{l}2 \text { Echogenic myocardial masses } \\
6 \text { Isolated valvular masses }\end{array}$ & $\begin{array}{l}2 \text { Hydatid cysts } \\
6 \text { Vallar masses, exclusion of } \\
\text { any associated lesion }\end{array}$ & $\begin{array}{l}\text { Pathology in } 1 \text { case } \\
\text { None, unchanged on } \\
\text { CSE follow up }\end{array}$ \\
\hline
\end{tabular}

HU, Hounsfield unit; CM, contrast media; RV, right ventricular; LV, left ventricular; LA, left atrial; RA, right atrial; SVC, superior vena cava; IVC, inferior vena cava; SPV, superior pulmonary venous.

the pathology of the cardiac lesions in the final two patients was related to the primary known malignant extracardiac lesion in one case and the primary operated cardiac lesion in the other. The group 2 patients comprised 40 with benign masses and 16 with malignant masses.

Benign masses (table 1)

Using EBT we found low density attenuation between -30 and 30 Hounsfield units (HU) in atrial myxomas within the left atrium in 10 cases and within the right atrium in one. Attachment to the interatrial septum was found in all cases by TOE and EBT. All myxomas were operated on, and the EBT findings were confirmed at surgery.

In the seven lipomatous lesions the density attenuation was around -80 Hounsfield units, similar to that of mediastinal fat. Two lesions were lipomas (fig 2), which remained stable after two years of echocardiographic follow up. Five lipomatous infiltrations of the atrial septum were clearly delineated by EBT. This diagnosis had been indicated by TOE in two cases, but the three others had been diagnosed as possible tumours or atypical features of mural thrombi.

Eight cardiac thrombi (endoluminal lesions) were found, despite the lack of typical features of thrombus on either TTE or TOE. Three cases in which both TOE and EBT images were suggestive of tumours finally proved to be thrombi at necropsy (one case) or after surgery (two cases). In five patients small lesions (three in the right atrium, one in the left atrium, and one in the right ventricle) were suggestive of thrombi when assessed by EBT because they appeared to be floating in the cavity without infiltrating the adjacent myocardial wall and because of their low CT attenuation even on delayed CT scans. These lesions disappeared after two to four months of anticoagulant treatment, when the patient was reviewed by EBT (three cases) or TOE (two cases), confirming the initial EBT diagnosis of thrombus.

Five of the six pericardial masses were detected by EBT as pericardial masses that were not enhanced after contrast injection. By cross sectional echocardiography such lesions were considered to be an atypical thrombus in one case, probably a pericardial haematoma in the second, and atrial tumours or pericardial tumours in the remaining three. The sixth pericardial mass case, which was suspected of being a pericardial tumour by cross sectional echocardiography, was found at EBT to have pericardial thickening involving the right atrial appendage. These findings were confirmed at surgery and were finally related to non-specific pericardial inflammation on pathological examination.

Two cases of hydatid cysts were detected by cross sectional echocardiography, and in both cases TOE revealed masses whose content was highly echogenic. However, only EBT provided the final diagnosis because the lesions had both a peripheral calcium ring and showed no enhancement after contrast medium injection, even in delayed scans. Furthermore, EBT also gave an accurate overall volume for the cysts and assessed their relations with adjacent structures better than did TOE.

In the six patients with valve lesions less than $20 \mathrm{~mm}$ in diameter detected by TOE, EBT clearly excluded associated masses. However, compared with TOE, display of the lesion by both the volume and cine mode of EBT was of lower quality than with TOE, and the lesion always appeared smaller on EBT. All of these lesions were discovered while there was no clinical evidence of embolism or sepsis, and none was operated on.

\section{Malignant masses (table 2)}

Of the 16 malignant masses, six were primary, including two lymphomas in patients with acquired immunodeficiency syndrome, one angiosarcoma, one leiomyosarcoma, one fibrosarcoma, and one recurrent epithelioid haemangioma. Among the eight other patients, only one malignant tumour was metastatic (bladder carcinoma); in the other 
Figure 2 Cardiac lipoma. ECG-gated cine EBT images at end diastole $(A)$ and a TOE image (B)

show a mass (upper arrow) originating from the myocardium between the papillary muscles (lower arrow). The mass occupies a large volume of the left ventricular chamber. Only $E B T$ demonstrates the fatty nature of the mass by showing its low density attenuation. ( $L V$, left ventricle; $L A$, left atrium).
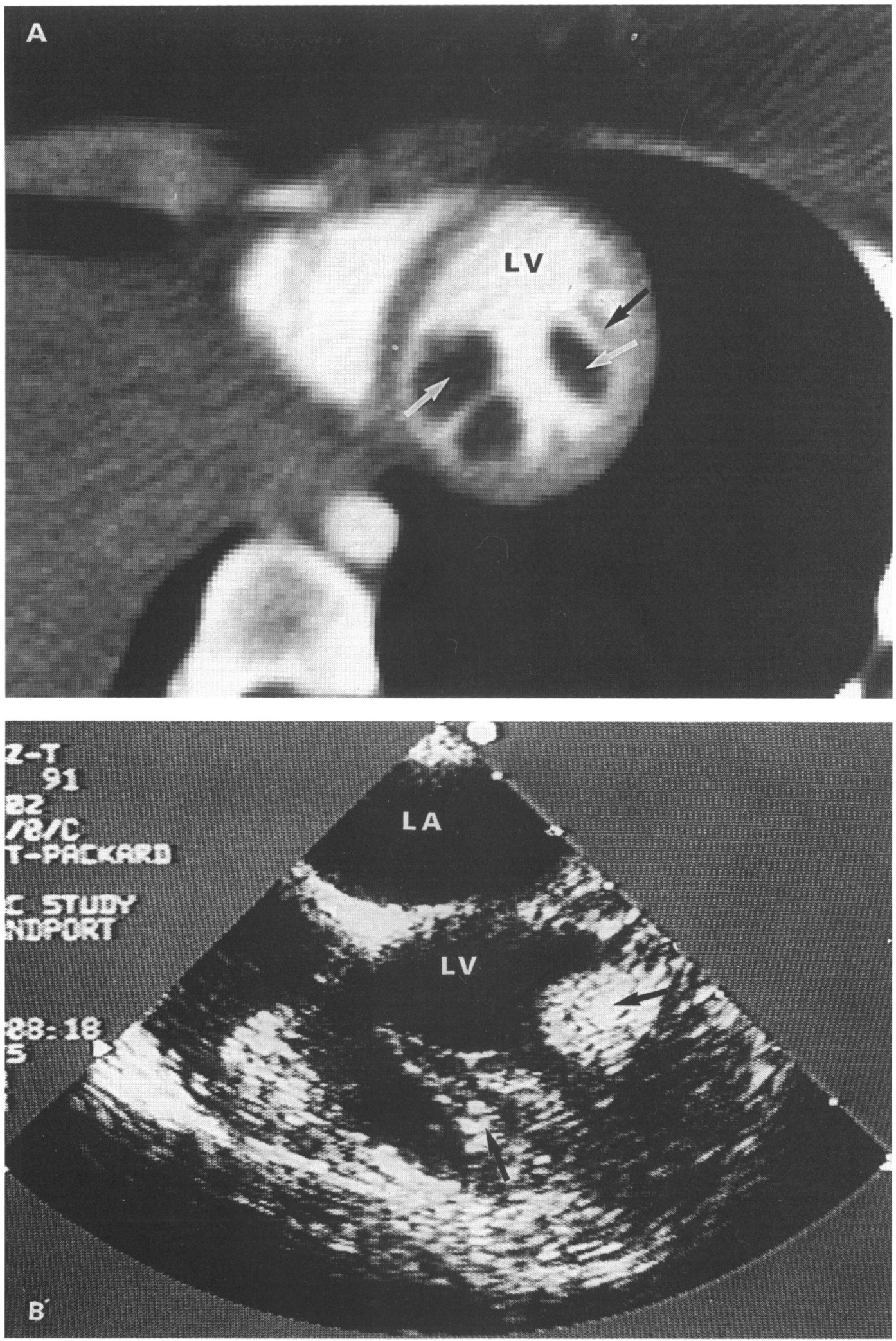

seven a mediastinal tumour had spread to the pericardium and heart (two thymomas, two epidermoid lung tumours, two mediastinal lymphomas, and one mediastinal pleural tumour involving both the pericardium and the lateral wall of the left ventricle). One case of bifocal schwannoma, primarily localised in the right knee and the left lung, recurred a year after surgery in the left lung associated with masses in the right and left ventricles. Such cardiac lesions were assumed to be malignant (fig 3). The last case was an invasive cardiac tumour in both the right ventricle and the right atrium, with pericardial involvement and many pulmonary nodular metastatic lesions (fig 4).

Additional information provided by EBT imaging after cross sectional echocardiography

In 53 cases (70\%) EBT modified the diagnosis or confirmed a diagnosis that had been questionable by cross sectional echocardiography. EBT findings in these cases included anatomical features and densely calcified or fatty struc- 
Table 2 Results of studies on group 2 patients with malignant masses

\begin{tabular}{|c|c|c|c|c|}
\hline Patient & Age/sex & $\begin{array}{l}\text { Cross sectional } \\
\text { echocardiography (CSE) }\end{array}$ & $E B T$ imaging & Pathology verification \\
\hline 1 & $38 / \mathrm{M}$ & RA mass & $\begin{array}{l}\text { RA mass extending into SVC and IVC } \\
\text { with mediastinal lymph nodes }\end{array}$ & $\begin{array}{l}\text { Primary cardiac } \\
\text { lymphoma }\end{array}$ \\
\hline 2 & $56 / M$ & $\begin{array}{l}\text { LA mass arising from } \\
\text { atrial septum }\end{array}$ & $\begin{array}{l}\text { LA mass extending to pericardium with } \\
\text { mediastinal lymph nodes }\end{array}$ & $\begin{array}{l}\text { Primary cardiac } \\
\text { lymphoma }\end{array}$ \\
\hline 3 & $44 / F$ & $\begin{array}{l}\text { LA mass extending into } \\
\text { SPV }\end{array}$ & $\begin{array}{l}\text { LA mass extending into SPV with } \\
\text { mediastinal lymph nodes }\end{array}$ & Angiosarcoma \\
\hline 4 & $59 / \mathrm{F}$ & $\begin{array}{l}\text { Possible RV thrombus or } \\
\text { RV tumour }\end{array}$ & $\begin{array}{l}\text { RV tumour extending into RA, } \\
\text { pericardium, and SVC }\end{array}$ & Leiomyosarcoma \\
\hline 5 & $60 / \mathrm{M}$ & $\begin{array}{l}\text { Bifocal tumour within } \\
\text { both the right atrium and } \\
\text { the right ventricle }\end{array}$ & $\begin{array}{l}\text { RV tumour with extension to the right } \\
\text { atrium }\end{array}$ & Fibrosarcoma \\
\hline 6 & $42 / \mathrm{M}$ & Lateral LV mass & $\begin{array}{l}\text { Infiltrative lateral LV mass with } \\
\text { pericardial involvement }\end{array}$ & $\begin{array}{l}\text { Supposed to be related } \\
\text { to the primary operated } \\
\text { LA epithelioid } \\
\text { haemangioma }\end{array}$ \\
\hline 7 & $60 / \mathrm{M}$ & RV tumour or thrombus & RV tumour with lung metastases & $\begin{array}{l}\text { Bladder carcinoma with } \\
\text { heart and lung } \\
\text { metastases }\end{array}$ \\
\hline 8 & $22 / \mathrm{F}$ & RV outflow mass & $\begin{array}{l}\text { Extracardiac tumour with RV and RA } \\
\text { involvement }\end{array}$ & Thymoma \\
\hline 9 & $77 / \mathrm{F}$ & Possible LV tumour & Infiltrative mediastinal tumour with & Thymoma \\
\hline 10 & $65 / F$ & $\begin{array}{l}\text { LA thrombus and LA } \\
\text { tumour of the lateral wall }\end{array}$ & $\begin{array}{l}\text { Pulmonary tumour involving the LA wall } \\
\text { associated with an intracavitary } \\
\text { neoplasic thrombus }\end{array}$ & $\begin{array}{l}\text { Epidermoid lung } \\
\text { carcinoma }\end{array}$ \\
\hline 11 & $67 / F$ & LA tumour & $\begin{array}{l}\text { Large pulmonary tumour involving the } \\
\text { LA wall }\end{array}$ & $\begin{array}{l}\text { Epidermoid lung } \\
\text { carcinoma }\end{array}$ \\
\hline 12 & 61/M & $\begin{array}{l}\text { Pericardial effusion with } \\
\text { possible RA tumour of } \\
\text { the lateral wall }\end{array}$ & $\begin{array}{l}\text { Mediastinal lymph nodes and } \\
\text { infiltrative tumour with pericardial, } \\
\text { RA and RV involvement }\end{array}$ & Lymphoma \\
\hline 13 & $69 / \mathrm{M}$ & RA tumour & $\begin{array}{l}\text { Mediastinal lymph nodes and } \\
\text { infiltrative tumour with pericardial } \\
\text { and RA involvement }\end{array}$ & Lymphoma \\
\hline 14 & $50 / \mathrm{M}$ & $\begin{array}{l}\text { Possible pericardial } \\
\text { tumour }\end{array}$ & $\begin{array}{l}\text { Mediastinal pleural tumour involving } \\
\text { both pericardium and the LV lateral wall }\end{array}$ & $\begin{array}{l}\text { Pleural and cardiac } \\
\text { metastases }\end{array}$ \\
\hline 15 & $35 / \mathrm{M}$ & $\begin{array}{l}\text { Association of RV and } \\
\text { LV tumours }\end{array}$ & $\begin{array}{l}\text { One RV tumour extending into the } \\
\text { pulmonary artery and one LV infiltrative } \\
\text { tumour associated with a post-surgical } \\
\text { recurrence in the left lung }\end{array}$ & $\begin{array}{l}\text { Supposed to be related } \\
\text { to the primary operated } \\
\text { lung schwannoma }\end{array}$ \\
\hline 16 & $34 / F$ & $\begin{array}{l}\text { RA and RV outflow } \\
\text { masses }\end{array}$ & $\begin{array}{l}\text { Large infiltrative cardiac tumour } \\
\text { extending into } R A, R V \text { in association } \\
\text { with lung metastases }\end{array}$ & None \\
\hline
\end{tabular}

RV, right ventricular; LV, left ventricular; LA, left atrial; RA, right atrial; CM, cardiomyopathy; SVC, superior vena cava; IVC, inferior vena cava; SPV, superior pulmonary venous.

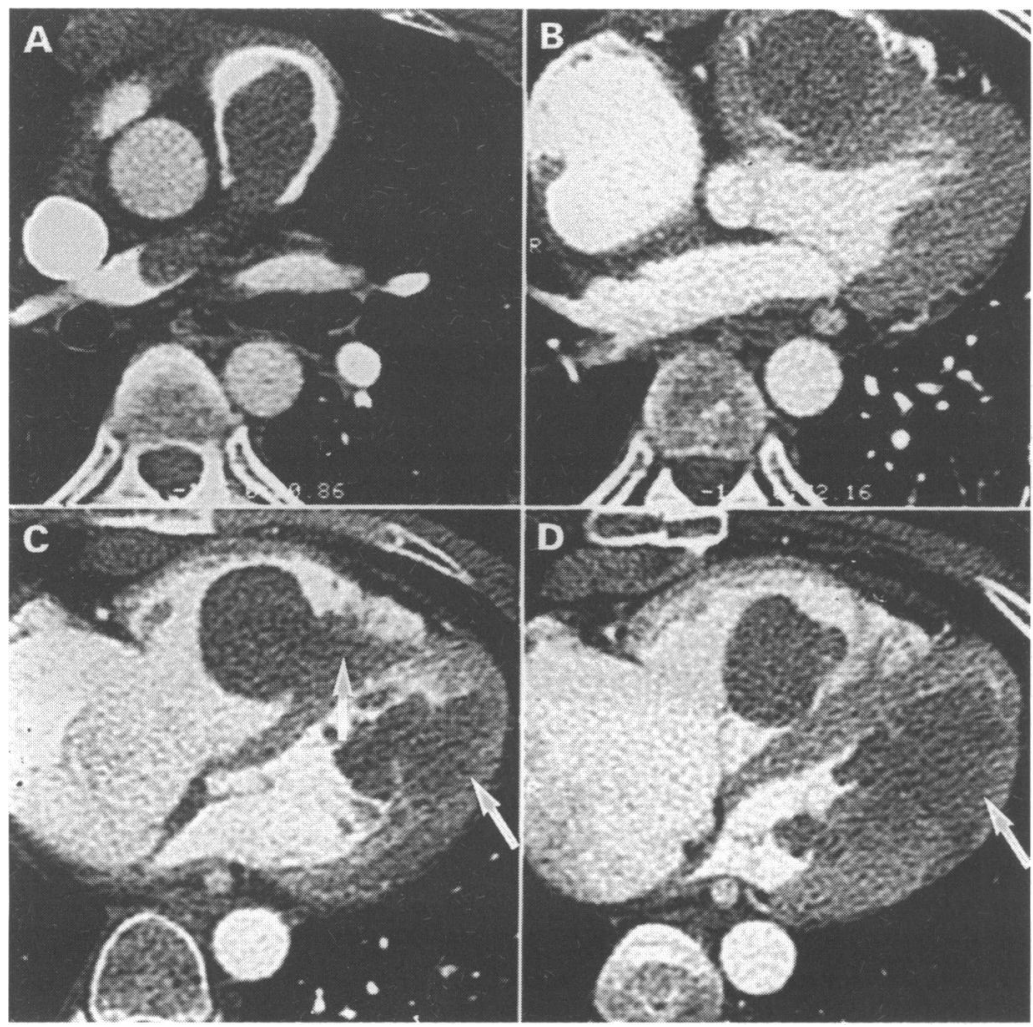

Figure 3 Bifocal cardiac schwannoma in the right and left ventricles. EBT axial images centred at the level of the main pulmonary artery $(A)$, the right-ventricular outflow tract $(B)$, and two midventricular levels $(C$ and $D)$. The right ventricular mass obliterates both the main pulmonary artery and right ventricular outflow tract. In $C$ the mass is clearly seen arising from the ventricular septum (upper arrow). The left ventricular tumour infiltrates the lateral wall of the left ventricle in both $C$ and $D$ (arrow). tures detected in the 20 group 1 patients. Other additional EBT findings consisted of confirming the fatty nature of five lipomatous lesions, showing the endocavitary location of five equivocal thrombi, and demonstrating the pericardial and avascular patterns of five pericardial masses (three haematomas, two cysts). In two other cases, non-enhanced masses and peripheral annular calcifications strongly suggested a hydatid cyst. Finally, in all 16 patients with malignant tumours, EBT provided additional anatomical information over cross sectional echocardiography. EBT provided better delineation of the relation between intracavity masses and normal structures, including the mural site of tumour attachment and tumour extensions.

In 19 cases, EBT provided little or no information in addition to cross sectional echocardiography. These cases included nine typical left atrial myxomas. In two other myxoma cases neither TOE nor EBT distinguished the lesion from other possible neoplasms. The lesion was in the right atrium in one and in the left atrium with atypical features in the other. In two cases of lipomatous infiltration of the atrial septum and six small valve lesions, EBT only confirmed the information provided by cross sectional echocardiography. However, in all 19 of these patients EBT showed that the lesions were well demarcated, limited in extent, and without any associated mass or tumour. 

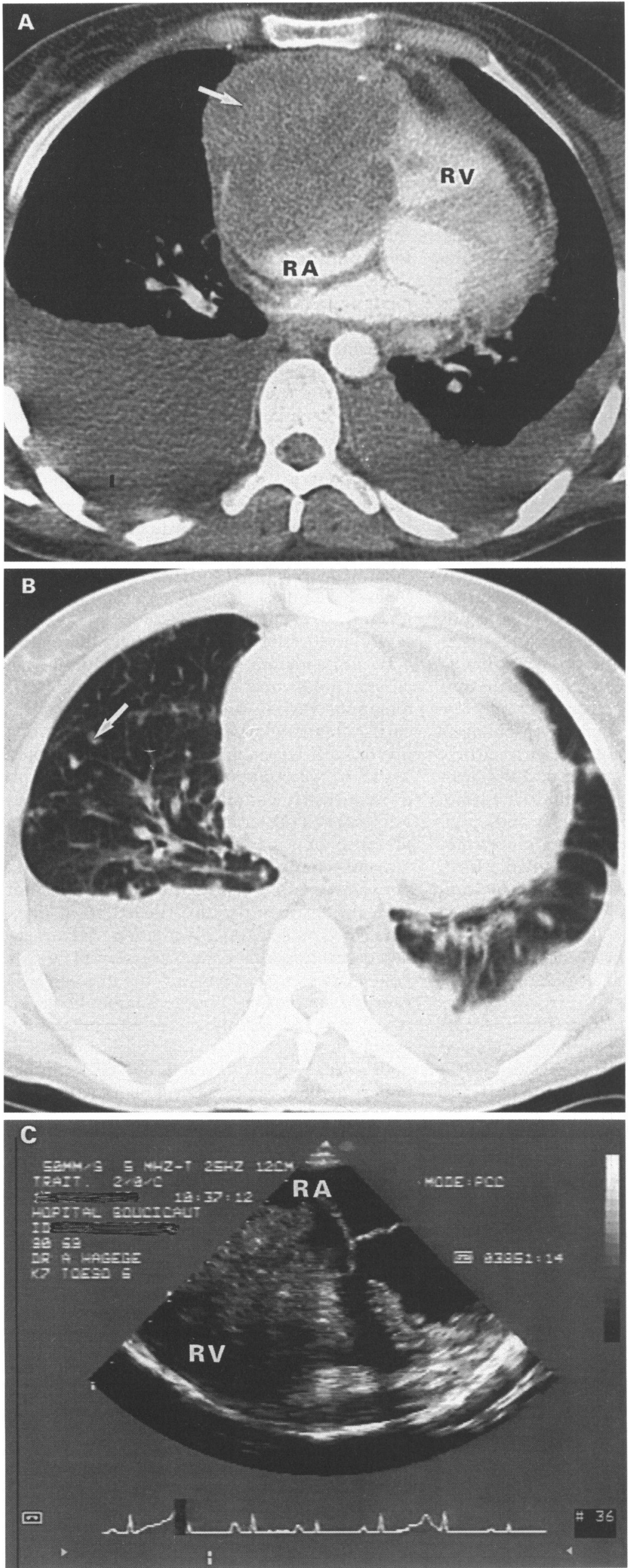

Figure 4 Large infiltrative tumour on two $100 \mathrm{~ms}$ EBT axial images ( $A$ and $B$ ) and one TOE image $(C)$. Both $E B T$ and TOE show the great extent of the tumour within the right atrium $(R A)$, the tricuspid ring, and the right ventricle (RV). However, only EBT demonstrates the lung metastasis (arrow) and the involvement of the pericardium (curved arrow), the superior vena cava, and the ascending aorta by tumour enlargement.

Masses in both TOE and EBT images in four cases were suggestive of tumours but this diagnosis was not confirmed at pathological examination. In two cases MRI was carried out and also confirmed a possible tumour. Atypical thrombi were finally found at surgery (two cases) or at necropsy (one case). Nonspecific pericardial inflammation was found after surgical biopsy in the last case.

Contribution of EBT imaging to decision making EBT imaging contributed to the decision for appropriate surgery in 17 cases: four malignant tumours with delimited extension (cases $3,4,5$, and 11), one pericardial serohaemorrhagic cyst, one hydatid cyst, and 11 myxomas. However, in nine typical left atrial myxomas, cross sectional echocardiography alone was sufficient to establish the need for surgery because EBT provided no additional information.

The information provided by EBT imaging contributed to a decision against surgery in 55 cases. In all group 1 cases $(n=20)$ and in patients with lipomatous lesions $(n=7)$, pericardial haematomas $(n=3)$, or pericardial cysts $(n=1)$, neither medical treatment nor surgery was deemed necessary after EBT findings. Five patients with equivocal evidence of thrombi at cross sectional echocardiography were treated with anticoagulation therapy after EBT confirmed a thrombus. In six patients with small valvar lesions, follow up echocardiographic studies were recommended because of the lack of further information as well as the absence of associated lesions at EBT findings. EBT imaging was useful in 13 patients because they had non-resectable lesions or a lymphoma requiring medical treatment. Lesions were non-resectable either because of the extent of myocardial involvement (six cases of diffuse malignant tumour (cases 6, 8, 9, 10, 14, and 15) and one case with a hydatid cyst) or because of lung metastases associated with the cardiac tumour (cases 7 and 16). In four patients, mediastinal biopsies of masses, recommended after EBT, confirmed the diagnosis of lymphoma (cases 1, 2, 12, and 13). Large lymph nodes associated with tumour involvement of the pericardium and/or the myocardium were diagnosed as lymphomas by EBT but were not detected by TOE.

\section{Discussion}

This study shows the clinical usefulness of EBT for evaluating of patients with cardiac masses suggested by TOE. EBT can play a significant part by confirming the presence of a mass and defining its extent and origin. EBT 
imaging also contributes substantially towards patient management and influences decisions for or against surgery.

By showing that anatomical features were the cause of the equivocal findings of cross sectional echocardiography, EBT excluded the diagnosis of an intracardiac mass in the group 1 patients.

In the group 2 patients with true intracardiac masses, EBT modified the diagnosis or confirmed a diagnosis which had been questionable using cross sectional echocardiography in 33 further cases. This means that in $70 \%$ (53 out of 76 ) of the cases EBT added important additional information to cross sectional echocardiography. However, EBT did not provide additional information in 19 group 2 cases. Most of these lesions were left atrial myxomas or valve lesions. Cine mode EBT (scan time of $50 \mathrm{~ms}$ ) plus the standard examination can be used to assess the mobility and haemodynamic effects of tumour masses. However, in cases with mobile intracavitary lesions, EBT provided no great advantage over TOE for determining the relation between the lesion and the valves and/or the extension of the lesion to adjacent normal intracardiac structures. In most patients, EBT imaging contributed to the decision making. This contribution was particularly important for malignant tumours. Although extracardiac tumours extending into cardiac chambers may be detected by transthoracic or transoesophageal ultrasound, information on the origins of these tumours and their extension beyond the heart was not always obtained with these methods. EBT affected clinical management and surgical planning because it provided a more complete visualisation of cardiac, mediastinal, pulmonary, pleural, and chest wall structures in a single examination. EBT was useful in deciding against surgery in non-resectable lesions, in deciding to remove delineated cardiac lesions surgically, and in planning mediastinal biopses.

There are limitations to the current study. Since all the patients were initially evaluated with routine TTE and TOE at several institutions, it was not possible to compare EBT and cross sectional echocardiography, nor was this our intention. The seemingly high rate of patients included in our study because they had anatomical features detected as potential tumours at cross sectional echocardiography $(26 \%)$, despite the use of TOE, may be due to the way they were selected. Those with anatomical features that have been described as potential echocardiographic pitfalls ${ }^{14-17}$ 28-30 and cases with difficult cross sectional echocardiographic examinations may have been preferentially recruited into our study, and the total number of patients evaluated by echocardiography for a suspected mass is unknown. However, a prospective study of the contribution of a new imaging method to the diagnosis of tumour initially detected by TTE is difficult to design, and to our knowledge has not yet been achieved. Patients with typical TOE features of cardiac thrombi and vegetations from bacterial endocarditis were excluded because TOE is currently regarded as the reference method and we included only patients with cardiac masses likely to benefit from EBT. Nevertheless, thrombi and vegetations were found either because their clinical presentation was atypical or because their features on echocardiography were equivocal. The satisfactory results obtained in cases of thrombi with an atypical TOE appearance accord with previous experience indicating that EBT is an important imaging technique for confirming intracardiac thrombi, especially in patients in whom echocardiography was difficult to perform or to interpret. ${ }^{1431}$

Magnetic resonance imaging can also be performed immediately after cross sectional echocardiography, because this method with multiplane acquisition ability has proved valuable for evaluating cardiac tumours without the need for contrast material and ionising radiation. ${ }^{16-24}$ However, before surgery or mediastinal biopsy many patients will also require $\mathrm{CT}$ for lung analysis after $\mathrm{MR}$ imaging and cross sectional echocardiography. Further studies exploring cardiac masses should be done to analyse the risk-benefit and cost-benefit ratios of these options (TTE, TOE, MR imaging, CT, and EBT).

We now perform EBT whenever there is an echocardiographic image of a tumour in adults, unless technically adequate echocardiography demonstrates an exclusively intracavitary left atrial mass that is characteristic of a myxoma. If an extensive tumour is suggested by TTE, we recommend immediate EBT to avoid a costly, less informative and sometimes unpleasant TOE examination. Similarly, if the presence of a cardiac mass is confirmed or remains equivocal by $\mathrm{TOE}$, we recommend performing EBT, provided the mass does not have the features typical of a left atrial myxoma, a thrombus, or a vegetation. MR imaging using spin-echo, cine acquisition and/or new sequences during breath holding can be a valuable alternative. This technique, however, does not detect parenchymal pulmonary lesions very well and spatial resolution is still poorer than that obtained by EBT during breath holding. Naturally, patients with renal compromise and allergies to contrast media should have MRI if cross sectional echocardiography suggests a cardiac tumour.

We thank Benoit Diebold and Albert Hagège for providing the TOE images. The original English text was edited by Owen Parkes.

1 Aschenberg W, Schluter M, Kremer P, Schroder E, Siglow $V$, Bleifeld $W$. Transesophageal two-dimensional echocardiography for the detection of left atrial appendage thrombus. $\mathcal{F} \mathrm{Am}$ Coll Cardiol 1986; 7:163-6.

2 Pop G, Sutherland G, Koudstaal P, Sit T, deJong G, Roelandt J. Transesophageal echocardiography in the Roelandt $\mathrm{J}$. Transesophageal echocardiography in the
detection of intracardiac embolic sources in patients with detection of intracardiac embolic sources in patients
transient ischemic attacks. Stroke 1990;21:560-5.

3 Pearson A, Labovitz A, Tatineni S, Gomez C. Superiority of transesophageal echocardiography in detecting cardiac of transesophageal echocardiography in detecting cardiac
source of embolism in patients with cerebral ischemia of source of embolism in patients with cerebral ischemi
uncertain etiology. $₹ \mathrm{Am}$ Coll Cardiol 1991;17:66-72.

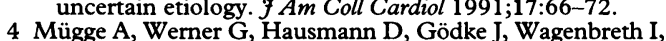
Lichtlen P. Diagnosis of left atrial appendage thrombi by Lichtlen P. Diagnosis of left atrial appendage thrombi by transesophageal echocardiography: clinical implication

and follow-up. Am f Cardiac Imaging 1990;4:173 9.
5 Reeder S, Khandheria B, Seward J, Tajik A. TransReeder S, Khandheria B, Seward J, Tajik A. Trans-
esophageal echocardiography and cardiac masses. Mayo esophageal echocardiograp
Clin Proc 1991;66:1 101-9.

6 Fyke FE, Seward JB, Edwards WD, Miller FA, Reeder GS, Schattenberg TT, et al. Primary cardiac tumors: 
experience with 30 consecutive patients since the introduction of two dimensional echocardiography. $\mathscr{f} \mathrm{Am} \mathrm{Coll}$

7 Obeid A, Marvasti M, Parker F, Rosenberg J. Comparison of transthoracic and transesophageal echocardiography in diagnosis of left atrial myxoma. Am $\mathcal{f}$ Cardiol 1989;63: 1006-8.

8 Engberding R, Erbel R, Kasper W, Lambertz H, Mügge A, Bogunovic N, et al. Diagnosis of heart tumors by transesophageal echocardiography -an European multicente study. Circulation 1989;80:II-474.

9 Daniel W, Mûgge A, Martin R, Lindert O, Hausmann D, Nonnast-Daniel $\mathrm{B}$, et al. Improvement in the diagnosis of abscesses associated with endocarditis by transesophageal echocardiography. $N$ Engl $f$ Med 1991;324: 795-800.

10 Shively B, Gurule F, Roldan C, Legget J, Schiller N. Diagnostic value of transesophageal compared with transthoracic echocardiography in infective endocarditis. transthoracic echocardiography in

11 Bateman T, Sethna D, Whiting J, Chaux A, Berman D, Forrester J. Comprehensive noninvasive evaluation of left atrial myxomas using cardiac cine-computed tomograatrial myxomas using cardiac cine-com

12 Minor R, Oren R, Standford W, Ferguson D. Biventricular thrombi and pulmonary emboli complicating idiopathic dilated cardiomyopathy: diagnosis with cardiac ultrafast CT. Am Heart F 1991;122:1477-81.

13 Rienmüller R, Tiling R. MR and CT for detection of cardiac tumors. Thorac Cardiovasc Surgeon 1990;38: 168-72.

14 Stanford W, Rooholamini S, Galvin J. Assessment of intracardiac masses and extracardiac abnormalities by ultrafast computed tomography. In: Marcus $\mathbf{M}$ Schelbert H, Skorton D, Wolf G, eds. Cardiac imaging. Philadelphia: Saunders, 1990:703-13.

15 Stanford W. Pseudomass at CT and MR imaging. Radiology 1992;182:876.

16 Lund JT, Ehman RL, Julsrud PR, Sinak LJ, Tajik AJ. Cardiac masses: assessment by MR imaging. $A \mathscr{F}$ 1989, 152:469-73.

17 Winkler $M$, Higgins CB. Suspected intracardiac masses evaluation with MR imaging Radiology 1987;165: 117-22.
18 Go RT, O'Donnell JK, Underwood DA, Feiglin DH, Salcedo EE, Pantoja M, et al. Comparison of gated cardiac MRI and 2D echocardiography of intracardiac neoplasms. AfR 1985;145:21-5.

19 Amparo EG, Higgins CB, Farmer D, Gordon G, McManara M. Gated MRI of cardiac and paracardiac masses: initial experience. $A f R$ 1984;143:1151-6.

20 Gomes AS, Lois JF, Child JS, Brown K, Batra P. Cardia tumors and thrombus: evaluation with MR imaging. $A \mathscr{F R}$ 1987;149:895-9.

21 Freedberg RS, Kronzon I, Rumancik WM, Liebeskind D. The contribution of magnetic resonance imaging to the evaluation of intracardiac tumors diagnosed by echocardiography. Circulation 1988;77:96-103.

22 Barakos J, Brown J, Higgins C. MR imaging of secondary cardiac and paracardiac lesions. AfR 1989;153:47-50.

23 Rienmüller R, Lloret $\mathrm{J}$, Tiling R, Groh J, Manert W, Müller $\mathrm{KD}$, et al. MR imaging of pediatric cardiac tumors previously diagnosed by echocardiography. $f$ tumors previously diagnosed by

24 Funari M, Fujita N, Peck W, Higgins C Cardiac tumors: assessment with Gd-DTPA enhanced MR imaging. $f$

25 Stanford W, Rooholamini S, Galvin J. Ultrafast computed tomography in the diagnosis of aortic aneurysms and distomography in the diagnosis of aortic a
section. $\mathcal{F}$ Thorac Imaging 1990;5:32-9.

26 Boyd DP, Couch JL, Napel SA, Peschmann KR, Rand RE Ultra cine-CT for cardiac imaging: where have we been? Uhtra cine-CT for cardiac imaging: where have we been

27 Hamada S, Takamiya M, Kimura K, Imakita S, Nakajima N, Naito $H$. Type A aortic dissection: evaluation with ultrafast CT. Radiology 1992;183:155-8.

28 Mirowitz S, Gutierrez F. Fibromuscular elements of the right atrium: pseudomass at MR imaging. Radiology 1992;182:231-3.

29 Kriegshauser JS, Julsrud PR, Lund JT. MR imaging of fat in and around the heart. $A f R 1990 ; 155: 271-4$.

30 Menegus M, Greenberg M, Spindola-Franco H, Fayemi A Magnetic resonance imaging of suspected atrial tumors. Am Heart f 1992;123:1260-8.

31 Beattie B, Struck L, Stanford Wea. Two dimensional echocardiography and ultrafast cardiac tomography for the detection of intra-cardiac thrombi in cerebral ischemia. Ann Neurol 1988;24:155A. 